\title{
Research Square \\ Late chronotype is linked to greater cortical thickness in the left fusiform and entorhinal gyri
}

Michal Rafal Zareba ( $\sim$ michal.zareba@student.uj.edu.pl ) Jagiellonian University: Uniwersytet Jagiellonski w Krakowie https://orcid.org/0000-0002-8525-2412

Magdalena Fafrowicz

Jagiellonian University: Uniwersytet Jagiellonski w Krakowie

Tadeusz Marek

Jagiellonian University: Uniwersytet Jagiellonski w Krakowie

\section{Ewa Beldzik}

Jagiellonian University: Uniwersytet Jagiellonski w Krakowie

\section{Halszka Oginska}

Jagiellonian University: Uniwersytet Jagiellonski w Krakowie

Aleksandra Domagalik

Jagiellonian University: Uniwersytet Jagiellonski w Krakowie

\section{Research Article}

Keywords: chronotype, MRI, VBM, cortical thickness, grey matter, white matter

Posted Date: June 8th, 2021

DOI: https://doi.org/10.21203/rs.3.rs-588446/v2

License: (c) (i) This work is licensed under a Creative Commons Attribution 4.0 International License. Read Full License

Version of Record: A version of this preprint was published at Biological Rhythm Research on October 19th, 2021. See the published version at https://doi.org/10.1080/09291016.2021.1990501. 


\section{Late chronotype is linked to greater cortical thickness in the left fusiform and entorhinal gyri}

Michal Rafal Zareba ${ }^{1,2 *}$, Magdalena Fafrowicz ${ }^{3}$, Tadeusz Marek ${ }^{3}$, Ewa Beldzik

${ }^{3}$, Halszka Oginska ${ }^{3}$, Aleksandra Domagalik ${ }^{2}$

${ }^{1}$ Institute of Zoology and Biomedical Research, Faculty of Biology, Jagiellonian University, Kraków, Poland

${ }^{2}$ Brain Imaging Core Facility, Malopolska Centre of Biotechnology, Jagiellonian University, Kraków, Poland

3 Department of Cognitive Neuroscience and Neuroergonomics, Institute of Applied Psychology, Jagiellonian University, Kraków, Poland

*Corresponding author's e-mail address: michal.zareba@ @student.uj.edu.pl 
Late chronotype is linked to greater cortical thickness in the left fusiform and entorhinal gyri

Humans can be classified as early, intermediate and late chronotypes based on the preferred sleep and wakefulness patterns. The anatomical basis of these distinctions remains largely unexplored. Using magnetic resonance imaging data from 113 healthy young adults (71 females), we aimed to replicate cortical thickness and grey matter volume chronotype differences reported earlier in the literature using a greater sample size, as well as to explore the volumetric white matter variation linked to contrasting circadian phenotypes. Instead of comparing the chronotypes, we correlated the individual chronotype scores with their morphometric brain measures. The results revealed one cluster in the left fusiform and entorhinal gyri showing increased cortical thickness with increasing preference for eveningness, potentially providing an anatomical substrate for chronotype-sensitive affective processing. No significant results were found for grey and white matter volume. We failed to replicate cortical thickness and volumetric grey matter distinctions in the brain regions reported in the literature. Furthermore, we found no association between white matter volume and chronotype. Thus, while this study confirms that circadian preference is associated with specific structural substrates, it adds to the growing concerns that reliable and replicable neuroimaging research requires datasets much larger than those commonly used.

Keywords: chronotype, MRI, VBM, cortical thickness, grey matter, white matter

\section{Introduction}

Human physiology is characterised by circadian rhythmicity. These patterns are evident at the cellular, system, and behavioural level (see Vadnie and McClung 2017 for review). The masterminds behind these rhythms are the suprachiasmatic nuclei, a pair of small structures located in the anterior part of the hypothalamus, above the optic chiasm. The circadian system enables temporal synchronisation of body physiology to the 
environmental cues (as reviewed in Logan and McClung 2019). Humans are known to vary in their preferred time of sleep and wakefulness, reflecting differential functioning of the above system. These individual differences in circadian rhythms are known as chronotypes. Despite the growing interest in functional brain imaging research in the field of chronobiology, studies regarding the anatomical differences in that context are still lacking.

Early chronotype (EC) is characterised by earlier hours of waking up, a preference for being active in the morning and earlier hours of going to sleep (Horne JA and Ostberg, 1976). Conversely, individuals with late chronotype (LC) tend to wake up later in the morning, exhibit more alertness in the afternoon or evening, and display a leaning towards staying up late. An intermediate chronotype (IC), characteristic for the majority of the population, is also distinguished. Compared to EC, LC has been linked to differences in a number of physiological variables (Lack et al. 2009) and behavioural domains, including emotional bias (Berdynaj et al. 2016), face processing (Berdynaj et al. 2016; Horne CM et al. 2016) and delay discounting (Evans and Norbury 2021). Also, LC are known to be prone to show more depressive symptoms (Hidalgo et al. 2009; GasparBarba et al. 2009) and other adaptational problems connected both with their social functioning specificity and physiological characteristics. The neural basis for this is not well-documented.

Studying the human brain structure in vivo is possible by applying magnetic resonance imaging (MRI). Such data represent the entire brain as a three-dimensional volume or solely the cerebral cortex as a two-dimensional sheet. The volumetric analyses can provide information regarding brain tissue volume or water diffusion (Ashburner and Friston 2000; Le Bihan et al. 2001), whereas the surfaces convey details regarding cortical thickness, surface area, gyrification or sulcal depth (Fischl and Dale 2000; Feczko et al. 
2007; Luders et al. 2006). Investigations into the human brain structure provide us with invaluable insight, helping us to better understand differential nervous system functioning in health versus disease (Navarri et al. 2020), as well as in contrasting phenotypes (Cox SR et al. 2019). While several neuroimaging studies have discovered correlations of certain chronotype behavioural features with brain activity (Horne CM and Norbury 2018; Hasler et al. 2013), the literature regarding their anatomical basis is scarce. To our knowledge, there are only two studies in which morphometric grey matter (GM) analyses were conducted in healthy young adults in the context of circadian phenotypes.

Takeuchi et al. (2015) reported that morningness was linked to greater GM volume in the orbitofrontal cortex, whereas eveningness was associated with greater GM values in the precuneus, cuneus, superior parietal lobule, middle occipital lobe, and superior occipital lobe. These findings were complemented by a study from Rosenberg et al. (2018), who showed that EC individuals had smaller GM volume in the lingual gyrus, occipital fusiform gyrus, and occipital pole compared to IC subjects, as well as in the precuneus and lateral occipital cortex compared to LC participants. In addition to this, they reported EC was associated with a lower cortical thickness than IC in the superior parietal lobe, as well as thinner cerebral cortex than LC in the insula, precuneus, inferior parietal lobe, and pars triangularis.

The aim of this study was to replicate the volumetric GM and cortical thickness distinctions between EC and LC reported by Rosenberg et al. (2018) using an independent, larger sample of healthy young adults. In addition to this, we performed a volumetric analysis on white matter (WM) data to further explore the anatomical basis of chronotype variability. 


\section{Materials and methods}

\section{Participants}

High-resolution structural data were taken from databases of two fMRI projects (2013/08/W/NZ3/00700 and 2013/08/M/HS6/00042). All participants were right-handed, had normal or corrected to normal vision, no neurological and psychiatric disorders, and were drugfree. The additional inclusion criteria comprised: no excessive daytime sleepiness as determined with Epworth Sleepiness Scale (ESS; Johns 1991; Chervin 2003), i.e. ESS $\leq 10$; good sleep quality as measured by Pittsburgh Sleep Quality Index (PSQI; Buysse et al. 1989), i.e. PSQI $\leq 5$; regular time-of-day schedule without sleep debt (between 6 and 9 hours of sleep per night); no shift work; not having been on a flight passing more than two time zones within the past two months; age between 19 and 35 years. The morningness-eveningness preference of the subjects was assessed with the Chronotype Questionnaire (Oginska 2011; Oginska et al. 2017). The participants' scores ranged from 11 to 32 (the theoretical range being 8-32 pts.). The higher the score, the more evening-oriented the individual.

Each subject underwent a scanning session in the evening. This enabled us to control the time-of-day effects on the morphometric measures (Trefler et al. 2016). After visual inspection of the preprocessed MRI data, three participants were excluded from the study due to unsatisfactory removal of non-brain tissue in the segmentation process. Thus, the final sample consisted of 113 subjects (71 females). Demographics and sleep characteristics are provided in the Appendix 1.

All the described analyses were conducted using anonymised data taken from two projects that had been approved by respective ethics committees. Every participant was informed about the procedures and goals of the study they volunteered in and gave their written 
consent; studies were conducted in accordance with ethical standards described in the Declaration of Helsinki.

\section{Data acquisition}

MRI was performed using a 3T scanner (Magnetom Skyra, Siemens) with a 20-channel or 64channel head/neck coil. High-resolution anatomical images were acquired using a T1 MPRAGE sequence (176 sagittal slices; $1 \times 1 \times 1.1 \mathrm{~mm} 3$ voxel size; $\mathrm{TR}=2300 \mathrm{~ms}$, TE $=2.98$ ms, flip angle $=9^{\circ}$, GRAPPA acceleration factor 2).

\section{Data analysis}

The acquired structural data was analysed in CAT12 with two different approaches: cortical thickness (Dahnke et al. 2013) and voxel-based morphometry (VBM; Ashburner and Friston 2000). The distribution of the morningness-eveningness scores from the Chronotype Questionnaire was tested for normality with the Kolmogorov-Smirnov test. Our data was found to have Gaussian distribution $(\mathrm{p}=0.12624)$, which validated the correlational analyses between the morphometric and behavioural measures.

\section{Cortical thickness analysis}

Estimation of cortical thickness in CAT12 was done using the projection-based thickness method. After tissue segmentation, the WM distance was estimated, and the local maxima were then projected onto GM voxels using a neighbouring relationship described by the WM distance. This allowed handling of partial voluming, sulcal blurring, and sulcal asymmetries without explicit sulcus reconstruction. The processing stream subsequently included topology correction, spherical mapping, and spherical registration (Yotter et al. 2011). The resulting cortical thickness meshes in the fsaverage space were smoothed with a 10 -mm Gaussian filter. 
The statistical analysis was done in SPM12 (Penny et al. 2006). The correlation between the cortical thickness and the morningness-eveningness preference was assessed with one-sample t-tests. Sex and age were controlled as covariates. Correction for multiple comparisons was achieved at the cluster level with the family-wise error correction (FWE; $\mathrm{p}<0.05)$ following the initial voxel-wise thresholding ( $\mathrm{p}<0.001$ uncorrected).

\section{Voxel-based morphometry analysis}

The default VBM pipeline in CAT12 software was applied, i.e. volumes underwent segmentation of GM, WM and cerebrospinal fluid, which was followed by spatial normalisation in the standardised MNI152 space using diffeomorphic anatomical registration through exponentiated lie algebra (DARTEL). Normalised GM and WM segments were then modulated using the Jacobian determinant in order to adjust for the resulting volume changes. All preprocessed GM and WM segments were subsequently checked visually to ensure the quality of the process. Lastly, each of the segmented, normalised, and modulated images was smoothed in SPM12 using a 4-mm Gaussian filter. The statistical analysis, separate for each tissue class, was performed in AFNI (Cox 1996) using the 3dMVM program (Chen et al. 2014). The correlation between the tissue volume and chronotype was calculated with ANCOVA, where sex, age, and total intracranial volume were modelled as covariates. The correction for multiple comparisons was performed with the cluster-level FWE $(\mathrm{p}<0.05)$ after voxel-level thresholding ( $\mathrm{p}<0.001$ uncorrected).

\section{Results}

\section{Cortical thickness}

The analysis revealed that the chronotype score was positively correlated with cortical thickness in the left fusiform and entorhinal gyri $(\mathrm{p}<0.05)$. The results are depicted in Table 1 and Figure 
<insert Table 1 near here>

<insert Figure 1 near here>

\section{Voxel-based morphometry}

No correlation between chronotype and tissue volume was found for both GM and WM segments $(\mathrm{p}<0.05)$.

\section{Discussion}

The cortical thickness analysis revealed that LC had a thicker cortex in the left fusiform and entorhinal gyri compared to EC. Both regions are implicated in processing sensory stimuli. The left fusiform gyrus is an important node in the network responsible for analysing facial information (Zhen et al. 2013), whereas the entorhinal gyrus is a structure integrating sensory input of all modalities (Kerr et al. 2007). Earlier reports have observed increased negative or decreased positive processing in LC individuals across a number of domains, such as attentional bias, emotional categorisation, recognition, and recall (Berdynaj et al. 2016). In addition to this, LC was linked to the elevated recognition of sad facial expressions (Berdynaj et al. 2016; Horne CM et al. 2016). These findings have been complemented by a report showing increased activity in LC in bilateral amygdalae when viewing fearful faces, which was accompanied by reduced task-related functional connectivity between the right amygdala and dorsal anterior cingulate cortex (Horne CM and Norbury 2018). While the aforementioned study offers one possible explanation for greater reactivity of LC to negative emotional faces, i.e. decreased inhibition of amygdala activity by dorsal anterior cingulate (Jhang et al. 2018; Etkin et al. 2006), the results stemming from our study offer two more potential pathways, which may act convergently with the above mechanism to enhance the activity of amygdalae. Firstly, the 
lateral nucleus of the amygdala receives high-level sensory input, mainly from the anterior parts of the temporal lobe, including the fusiform gyri (Saygin et al. 2011). Secondly, the entorhinal cortex innervates all amygdalar nuclei (Kerr et al. 2007). The above implications should be validated by future studies investigating how cortical structure corresponds to task-related amygdalar activation during the presentation of negative emotional faces.

Our analyses found no correlation between chronotype and VBM results. Well-powered studies have shown that the effect sizes of volumetric GM differences between chronotypes range from marginal to small in both young and older adults (Takeuchi et al. 2015; Norbury 2020). Thus, we believe that the lack of such findings in our case quite likely stems from the inclusion of too few subjects. This could also hold true for volumetric WM distinctions, however, we cannot assess it with certainty as, to the best of our knowledge, no studies have reported such chronotype comparisons. Regarding the cortical thickness results, it would be beneficial to know the magnitude of the effects reported by the replicated study (Rosenberg et al. 2018), however, the data provided in the article is insufficient for the calculations. Nevertheless, it has been shown that smaller samples considerably overestimate the actual differences (Reddan et al. 2017). Thus, it would be difficult to compare them directly to our findings (113 subjects in our case versus 48 subjects in the original paper). Furthermore, having in mind that effect sizes are significantly inflated even in samples as large as 150 participants (Cremers et al. 2017), the magnitudes of the results reported in our study are quite possibly overstated as well. For more details regarding the effect sizes across the literature, please see Appendix 2.

While the current study found two new sites of anatomical differences associated with chronotype variability, it failed to achieve the goal of replicating the GM distinctions reported in the earlier papers (Rosenberg et al. 2018; Takeuchi et al. 2015). The unsuccessful replication of the literature results despite using a comparable methodology (i.e. controlling for sleep 
problems, similar scanning sequences, time of data acquisition and smoothing parameters) only adds to the growing concerns in the neuroimaging field (Turner et al. 2018). A recent report has found that over $70 \%$ of published structural MRI studies deployed cohorts smaller than 100 subjects (Szucs and Ioannidis 2020). Apart from the effect size overestimation mentioned earlier, the low number of participants also leads to a decrease in the ability to detect true results, adding to the replicability crisis (Cremers et al. 2017; Reddan et al. 2017; Turner et al. 2018). Due to the high costs of acquiring neuroimaging data, gathering large enough datasets often pose great challenges to single research facilities. In such cases, the appropriate means for resolving the former problem lie in the use of massive open databases like UK Biobank (Sudlow et al. 2015) or orchestrating international co-operations the likes of the ENIGMA Consortium (Thompson et al. 2014). Through the application of the above methods, future analyses should investigate the cortical thickness and diffusion-weighted imaging correlates of circadian phenotypes to reliably detect the effects and estimate their magnitude. It would also be beneficial to study the interplay between chronotype, brain structure, and behaviour.

In conclusion, our study revealed two new regions associated with chronotype variability yet did not replicate the earlier results. While this investigation further supports the notion that circadian preference is linked to specific anatomical substrates, it also underlines the need for using larger datasets for reliable and replicable neuroimaging.

\section{Acknowledgements}

MRZ, MF, TM and AD: conception and design of the work. MRZ, MF, EB, HO, AD: acquisition and analysis. MRZ, EB, AD: interpretation of the results. MRZ: drafting the work. MRZ, MF, EB, HO, TM and AD: revising the manuscript critically and final approval of the version to be published. All authors contributed to the article and approved the submitted version. 


\section{Declarations}

\section{Funding}

This research was supported by the Polish National Science Centre (NCN) grants 2013/08/M/HS6/00042 and 2013/08/W/NZ3/00700.

\section{Data availability}

The datasets analysed during this study will be made available upon article acceptance.

\section{Conflicts of interest}

The authors have no conflicts of interest to declare that are relevant to the content of this article.

\section{References}

Ashburner J, Friston KJ. 2000. Voxel-based morphometry - the methods. Neuroimage 11(6):805-821. https://doi.org/10.1006/nimg.2000.0582

Berdynaj D, Boudissa SN, Grieg MS, Hope C, Mahamed SH, Norbury R. 2016. Effect of chronotype on emotional processing and risk taking. Chronobiol Int. 33(4):406-18. https://doi.org/10.3109/07420528.2016.1146739

Buysse DJ, Reynolds CF 3rd, Monk TH, Berman SR, Kupfer DJ. 1989. The Pittsburgh Sleep Quality Index: a new instrument for psychiatric practice and research. Psychiatry Res 28(2):193-213. https://doi.org/10.1016/0165-1781(89)90047-4

Chen G, Adleman NE, Saad ZS, Leibenluft E, Cox RW. 2014. Applications of Multivariate Modeling to Neuroimaging Group Analysis: A Comprehensive Alternative to Univariate General Linear Model. $\quad$ Neuroimage 99:571-588. 
https://doi.org/10.1016/j.neuroimage.2014.06.027

Chervin RD. 2003. Epworth sleepiness scale. Sleep Med 4(3):175-176. https://doi.org/10.1016/S1389-9457(03)00030-3

Cox RW. 1996. AFNI: software for analysis and visualization of functional magnetic resonance neuroimages. Comput Biomed Res. 29(3):162-173. https://doi.org/10.1006/cbmr.1996.0014

Cox SR, Ritchie SJ, Fawns-Ritchie C, Tucker-Drob EM, Deary IJ. 2019. Structural brain imaging correlates of general intelligence in UK Biobank. Intelligence 76:101376. https://doi.org/10.1016/j.intell.2019.101376

Cremers HR, Wager TD, Yarkoni T. 2017. The relation between statistical power and inference in fMRI. PLoS One 12(11):e0184923. https://doi.org/10.1371/journal.pone.0184923

Dahnke R, Yotter RA, Gaser C. 2013. Cortical thickness and central surface estimation. Neuroimage 65:336-48. https://doi.org/10.1016/j.neuroimage.2012.09.050.

Etkin A, Egner T, Peraza DM, Kandel ER, Hirsch J. 2006. Resolving emotional conflict: a role for the rostral anterior cingulate cortex in modulating activity in the amygdala. Neuron 51(6):871-82. https://doi.org/10.1016/j.neuron.2006.07.029

Evans SL, Norbury R. 2021. Associations between diurnal preference, impulsivity and substance use in a young-adult student sample. Chronobiol Int. 38(1):79-89. https://doi.org/10.1080/07420528.2020.1810063

Feczko E, Augustinack JC, Fischl B, Dickerson BC. 2007. An MRI-based method for measuring volume, thickness and surface area of entorhinal, perirhinal, and posterior $\begin{array}{llll}\text { parahippocampal } & \text { cortex. } & \text { Neurobiol } & \text { Aging }\end{array}$ 420-31. https://doi.org/10.1016/j.neurobiolaging.2007.07.023 
Fischl B, Dale AM. 2000. Measuring the Thickness of the Human Cerebral Cortex from Magnetic Resonance Images. Proc. Natl. Acad. Sci. U.S.A 97:11044-11049. https://doi.org/10.1073/pnas.200033797

Gaspar-Barba E, Calati R, Cruz-Fuentes CS, Ontiveros-Uribe MP, Natale V, De Ronchi D, Serretti AJ. 2009. Depressive symptomatology is influenced by chronotypes. J Affect Disord. 119(1-3):100-6. https://doi.org10.1016/j.jad.2009.02.021

Hasler BP, Sitnick SL, Shaw DS, Forbes EE. 2013. An altered neural response to reward may contribute to alcohol problems among late adolescents with an evening chronotype. Psychiatry Res. Neuroimaging 214(3):357-364. https://doi.org/10.1016/j.pscychresns.2013.08.005

Hidalgo MP, Caumo W, Posser M, Coccaro SB, Camozzato AL, Chaves ML. 2009. Relationship between depressive mood and chronotype in healthy subjects. Psychiatry Clin Neurosci. 63(3):283-90. https://doi.org/10.1111/j.1440-1819.2009.01965.x

Horne CM, Marr-Phillips SDM, Jawaid R, Gibson EL, Norbury R. 2016. Negative emotional biases in late chronotypes. Biol. Rhythm Res. 48(1):151-155. https://doi.org/10.1080/09291016.2016.1236461

Horne CM, Norbury R. 2018. Late chronotype is associated with enhanced amygdala reactivity and reduced fronto-limbic functional connectivity to fearful versus happy facial expressions. Neuroimage 171:355-363. https://doi.org/10.1016/j.neuroimage.2018.01.025

Horne JA, Ostberg O. 1976. A self-assessment questionnaire to determine morningnesseveningness in human circadian rhythms. Int J Chronobiol. 4(2):97-110.

Jhang J, Lee H, Kang MS, Lee HS, Park H, Han JH. 2018. Anterior cingulate cortex and its input to the basolateral amygdala control innate fear response. Nat Commun. 9(1):2744. 
https://doi.org/10.1038/s41467-018-05090-y

Johns MW. 1991. A new method for measuring daytime sleepiness: the Epworth sleepiness scale. Sleep 14(6):540-5. https://doi.org/10.1093/sleep/14.6.540

Kerr KM, Agster KL, Furtak SC, Burwell RD. 2007. Functional neuroanatomy of the parahippocampal region: The lateral and medial entorhinal areas. Hippocampus 17(9):697-708. https://doi.org/10.1002/hipo.20315

Lack L, Bailey M, Lovato N, Wright H. 2009. Chronotype differences in circadian rhythms of temperature, melatonin, and sleepiness as measured in a modified constant routine protocol. Nat Sci Sleep. 1:1-8. https://doi.org/10.2147/nss.s6234

Le Bihan D, Mangin JF, Poupon C, Clark CA, Pappata S, Molko N, Chabriat H. 2001. Diffusion tensor imaging: concepts and applications. J Magn Reson Imaging. 13(4):534-46. https://doi.org/10.1002/jmri.1076

Logan RW, McClung CA. 2019. Rhythms of life: circadian disruption and brain disorders across the lifespan. Nat. Rev. Neurosci. 20:49-65. https://doi.org/10.1038/s41583-018-0088-y Luders E, Thompson PM, Narr KL, Toga AW, Jancke L, Gaser C. 2006. A curvature-based approach to estimate local gyrification on the cortical surface. Neuroimage 29(4):1224-30. https://doi.org/10.1016/j.neuroimage.2005.08.049

Navarri X, Afzali M, Lavoie J, Sinha R, Stein D, Momenan R, Veltman D, Korucuoglu O, Sjoerds Z, van Holst R, Hester R, London E, Orr C, Cousijn J, Yücel M, Thompson P, Mackey S, Conrod P. 2020. How do substance use disorders compare to other psychiatric conditions on structural brain abnormalities? A cross-disorder meta-analytic comparison using the ENIGMA Consortium findings. Hum. Brain Mapp. 1-15. https://doi.org/10.1002/hbm.25114 
Norbury R. 2020. Diurnal Preference and Grey Matter Volume in a Large Population of Older Adults: Data from the UK Biobank. J. Circadian Rhythms 18(1):3. https://doi.org/10.5334/jcr.193

Oginska H. 2011. Can you feel the rhythm? A short questionnaire to describe two dimensions of chronotype. Pers. Individ. Differ. 50(7):1039-1043. https://doi.org/10.1016/j.paid.2011.01.020

Oginska H, Mojsa-Kaja J, Mairesse O. 2017. Chronotype description: In search of a solid subjective amplitude scale. Chronobiol. Int. 34(10):1388-1400. https://doi.org/10.1080/07420528.2017.1372469

Penny W, Friston K, Ashburner J, Kiebel S, Nichols T. 2006. Statistical Parametric Mapping: The Analysis of Functional Brain Images 1st Edition. Cambridge (MA): Academic Press.

Reddan MC, Lindquist MA, Wager TD. 2017. Effect Size Estimation in Neuroimaging. JAMA Psychiatry. 74(3):207-208. https://doi.org/10.1001/jamapsychiatry.2016.3356

Rosenberg J, Jacobs HIL, Maximov II, Reske M, Shah NJ. 2018. Chronotype differences in cortical thickness: grey matter reflects when you go to bed. Brain Struct. Funct. 223(7): 34113421. https://doi.org/10.1007/s00429-018-1697-y

Saygin ZM, Osher DE, Augustinack J, Fischl B, Gabrieli JD. 2011. Connectivity-based segmentation of human amygdala nuclei using probabilistic tractography. Neuroimage 56(3):1353-1361. https://doi.org/10.1016/j.neuroimage.2011.03.006

Sudlow C, Gallacher J, Allen N, Beral V, Burton P, Danesh J, Downey P, Elliott P, Green J, Landray M, et al. 2015. UK Biobank: An Open Access Resource for Identifying the Causes of a Wide Range of Complex Diseases of Middle and Old Age. PLOS Medicine, 12(3), e1001779. 
https://doi.org/10.1371/journal.pmed.1001779

Szucs D, Ioannidis JP. 2020. Sample size evolution in neuroimaging research: an evaluation of highly-cited studies (1990-2012) and of latest practices (2017-2018) in high-impact journals. Neuroimage 221:117164. https://doi.org/10.1016/j.neuroimage.2020.117164

Takeuchi H, Taki Y, Sekiguchi A, Nouchi R, Kotozaki Y, Nakagawa S, Miyauchi CM, Iizuka K, Yokoyama R, Shinada T, et al. 2015. Regional gray matter density is associated with morningness-eveningness: Evidence from voxel-based morphometry. Neuroimage 117:294304. https://doi.org/10.1016/j.neuroimage.2015.05.037

Thompson PM, Stein JL, Medland SE, Hibar DP, Vasquez AA, Renteria ME, Toro R, Jahanshad N, Schumann G, Franke B, et al. 2014. The ENIGMA Consortium: large-scale collaborative analyses of neuroimaging and genetic data. Brain Imaging Behav. 8(2):153-82. https://doi.org/10.1007/s11682-013-9269-5

Trefler A, Sadeghi N, Thomas AG, Pierpaoli C, Baker CI, Thomas C. 2016. Impact of timeof-day on brain morphometric measures derived from T1-weighted magnetic resonance imaging. Neuroimage 133:41-52. https://doi.org/10.1016/j.neuroimage.2016.02.034

Turner BO, Paul EJ, Miller MB, Barbery AK. 2018. Small sample sizes reduce the replicability of task-based fMRI studies. Commun. Biol. 1(62). https://doi.org/10.1038/s42003-018-0073-z

Vadnie C, McClung C. 2017. Circadian Rhythm Disturbances in Mood Disorders: Insights into the Role of the Suprachiasmatic Nucleus. Neural Plast. 2017:1-28. https://doi.org/10.1155/2017/1504507

Yotter RA, Dahnke R, Thompson PM, Gaser C. 2011. Topological correction of brain surface meshes using spherical harmonics. Hum Brain Mapp. 32(7):1109-24. 
https://doi.org/10.1002/hbm.21095

Zhen Z, Fang H, Liu J. 2013. The hierarchical brain network for face recognition. PLoS One 8(3):e59886. https://doi.org/10.1371/journal.pone.0059886 
Appendix 1. Demographic and sleep characteristics of the sample.

\begin{tabular}{|l|l|}
\hline Variables & Mean \pm SD \\
\hline Sex (M/F) & $42 / 71$ \\
\hline Age (years) & $24.23 \pm 3.48$ \\
\hline ME & $21.58 \pm 5.70$ \\
\hline AM & $20.72 \pm 3.69$ \\
\hline PSQI & $2.94 \pm 1.20$ \\
\hline ESS & $6.12 \pm 2.76$ \\
\hline SD - standard deviation, ME - morningness/eveningness scale from the Chronotype
\end{tabular}

Questionnaire, AM - amplitude scale from the Chronotype Questionnaire, PSQI - Pittsburgh

Sleep Quality Index, ESS - Epworth Sleepiness Scale. 
Appendix 2. Effect sizes of grey matter voxel-based morphometry chronotype differences reported in the literature.

\begin{tabular}{|c|c|c|c|c|}
\hline Study & Location & Directionality & p value & Effect size \\
\hline Takeuchi et al. 2015 & $\mathrm{R}$ orbitofrontal cortex & $\begin{array}{l}\text { correlated } \\
\text { with EC }\end{array}$ & $\mathrm{p}<0.05$ & $\begin{array}{l}0.15 \\
\text { (Cohen's F) }\end{array}$ \\
\hline Takeuchi et al. 2015 & L orbitofrontal cortex & $\begin{array}{l}\text { correlated } \\
\text { with EC }\end{array}$ & $\mathrm{p}<0.05$ & $\begin{array}{l}0.14 \\
\text { (Cohen's F) }\end{array}$ \\
\hline Takeuchi et al. 2015 & $\begin{array}{l}\text { B precuneus } \\
\text { B cuneus }\end{array}$ & $\begin{array}{l}\text { correlated } \\
\text { with LC }\end{array}$ & $\mathrm{p}<0.05$ & $\begin{array}{l}0.20 \\
\text { (Cohen's F) }\end{array}$ \\
\hline Takeuchi et al. 2015 & $\begin{array}{l}\text { L superior parietal lobule } \\
\text { L middle occipital lobe } \\
\text { L superior occipital lobe }\end{array}$ & $\begin{array}{l}\text { correlated } \\
\text { with LC }\end{array}$ & $\mathrm{p}<0.05$ & $\begin{array}{l}0.16 \\
\text { (Cohen's F) }\end{array}$ \\
\hline Norbury 2020 & B precuneus & $\mathrm{EC}<\mathrm{LC}$ & $\mathrm{p} \leq 0.05$ & $\begin{array}{l}0.10 \\
\text { (Cohen's D) }\end{array}$ \\
\hline Norbury 2020 & $\begin{array}{l}\text { B thalamus } \\
\text { B nucleus accumbens } \\
\text { B caudate } \\
\text { B putamen } \\
\text { B pallidum }\end{array}$ & $\mathrm{EC}<\mathrm{LC}$ & $\mathrm{p} \leq 0.05$ & $\begin{array}{l}0.12 \\
\text { (Cohen's D) }\end{array}$ \\
\hline Norbury 2020 & $\begin{array}{l}\mathrm{R} \text { orbitofrontal cortex } \\
\mathrm{R} \text { frontal pole }\end{array}$ & $\mathrm{EC}<\mathrm{LC}$ & $\mathrm{p} \leq 0.05$ & $\begin{array}{l}0.11 \\
\text { (Cohen's D) }\end{array}$ \\
\hline
\end{tabular}




\begin{tabular}{|c|c|c|c|c|}
\hline Norbury 2020 & $\mathrm{R}$ inferior frontal gyrus & $\mathrm{EC}<\mathrm{LC}$ & $\mathrm{p} \leq 0.05$ & $\begin{array}{l}0.12 \\
\text { (Cohen's D) }\end{array}$ \\
\hline Norbury 2020 & $\begin{array}{l}\text { L orbitofrontal cortex } \\
\text { L frontal pole }\end{array}$ & $\mathrm{EC}<\mathrm{LC}$ & $\mathrm{p} \leq 0.05$ & $\begin{array}{l}0.10 \\
\text { (Cohen's D) }\end{array}$ \\
\hline Norbury 2020 & $\begin{array}{l}\text { L orbitofrontal cortex } \\
\text { L frontal pole }\end{array}$ & $\mathrm{EC}<\mathrm{LC}$ & $\mathrm{p} \leq 0.05$ & $\begin{array}{l}0.10 \\
\text { (Cohen's D) }\end{array}$ \\
\hline
\end{tabular}

B - bilateral, L - left, R - right, EC - early chronotype, LC - late chronotype. 
Table 1. Results of cortical thickness analysis performed at the level of $p<0.05$. The effect size of the reported correlation is described with Cohen's $\mathrm{f}$.

\begin{tabular}{|l|l|l|l|l|l|l|}
\hline & & & & Pearson's & & \\
Cluster no. & Coordinates & Vertices & Location & coefficient & Cohen's f & t-stat \\
\hline 1 & $-23,-19,-28$ & 292 & L entorhinal & 0.40 & 0.44 & 4.66 \\
\hline
\end{tabular}

$\mathrm{L}-$ left. 
Figure 1. Results of the correlational analysis between cortical thickness and chronotype score.

One cluster with positive correlation was found in the left fusiform and entorhinal gyri.

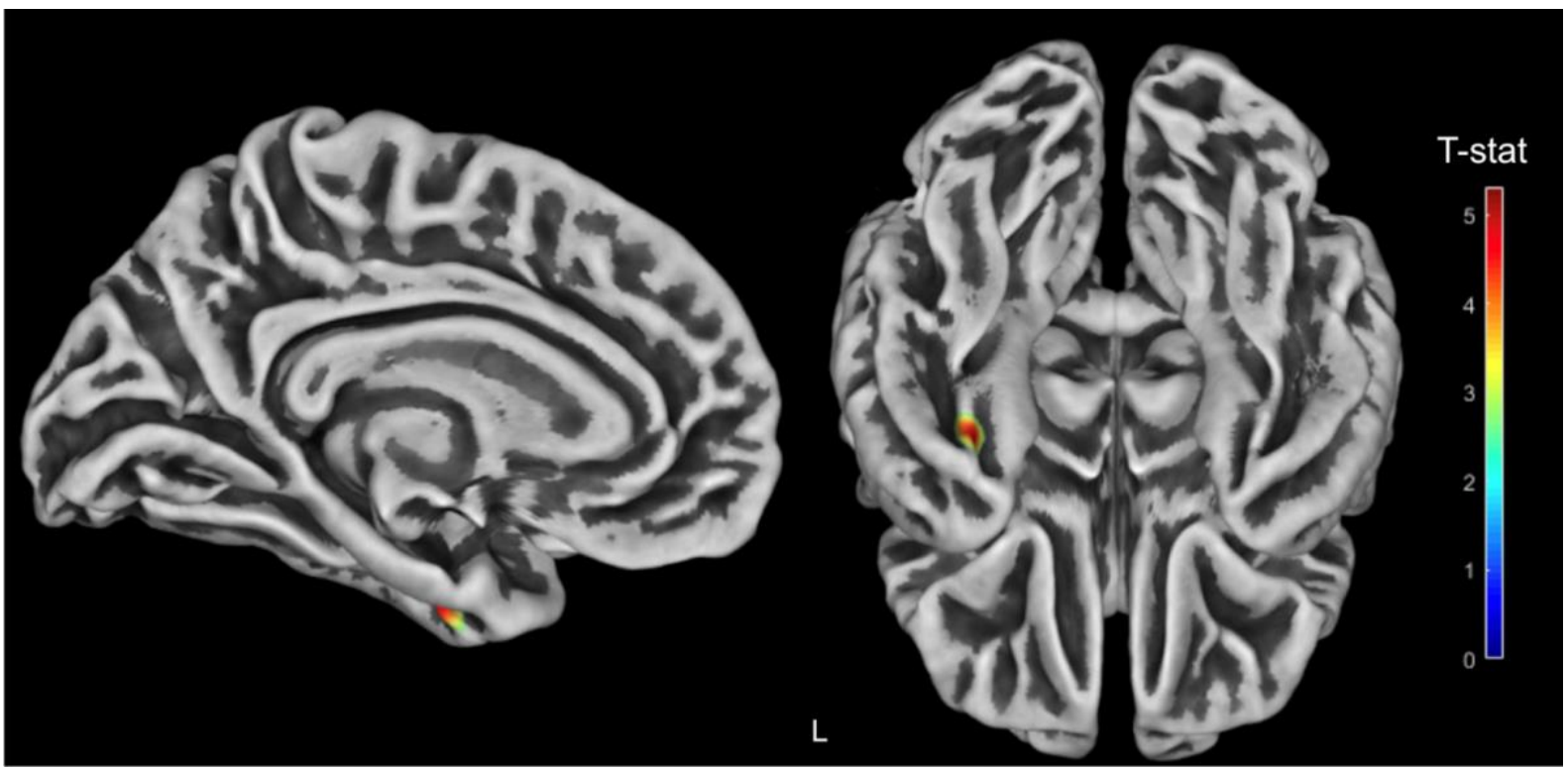




\section{Figures}

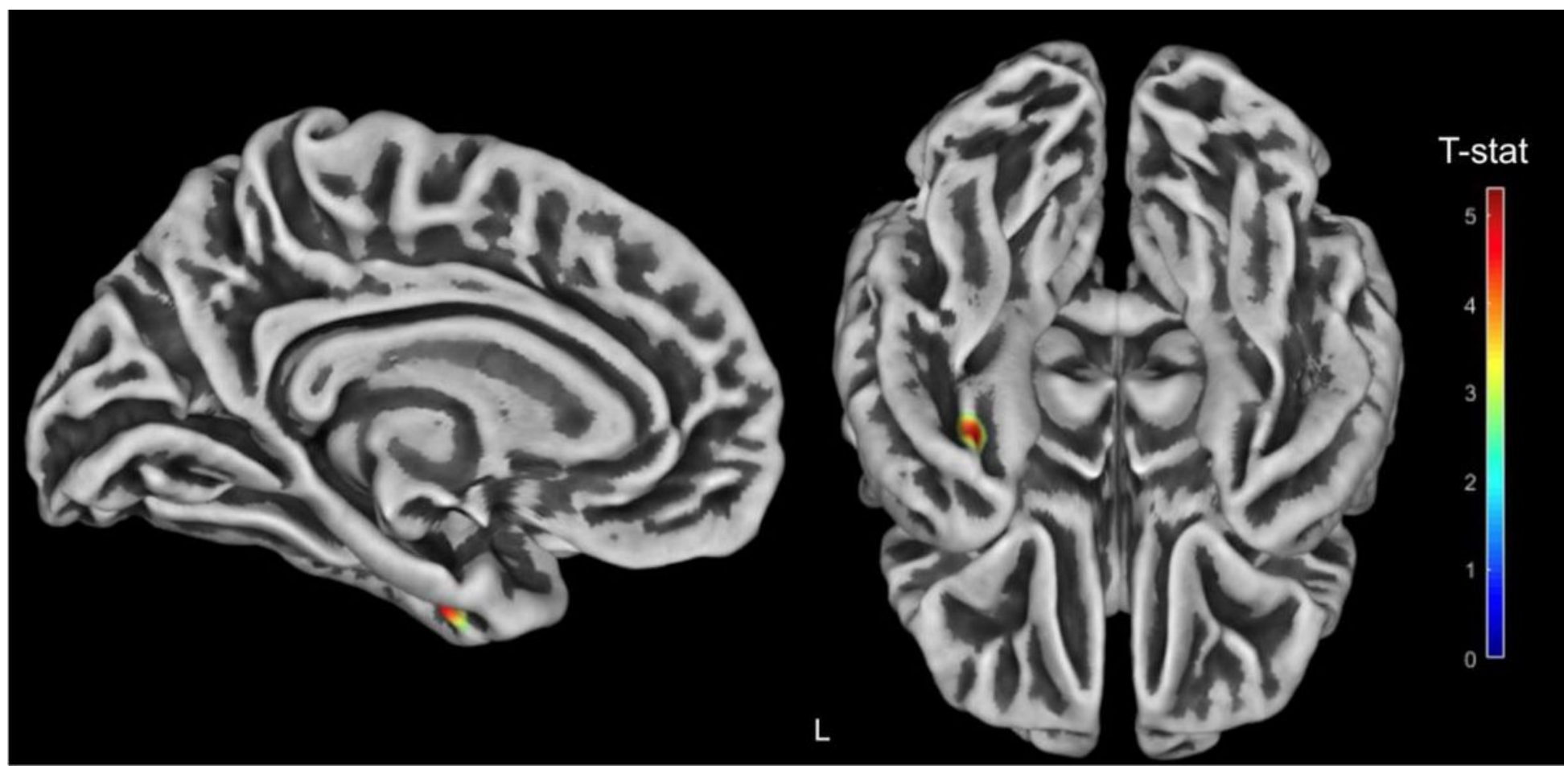

\section{Figure 1}

Results of the correlational analysis between cortical thickness and chronotype score. One cluster with positive correlation was found in the left fusiform and entorhinal gyri.

\section{Supplementary Files}

This is a list of supplementary files associated with this preprint. Click to download.

- OnlineResourceA1.pdf

- OnlineResourceA2.pdf 